\title{
OPTIMIZATION TO INCREASE ENERGY EFFICIENCY OF A SIROCCO CENTRIFUGAL FAN USING COMPUTATIONAL FLUID DYNAMICS (CFD)
}

\author{
L. B. Kothe, \\ A. P. Petry, \\ ABSTRACT \\ T. D. J. Vecina, \\ This paper presents a numerical and experimental study on the aerodynamic \\ performance of Sirocco centrifugal fans seeking an increase in energy \\ efficiency. Numerical simulations are performed by the Finite-Volume \\ Method commercial code ANSYS Fluent. Characteristics such as flow rate \\ at the outlet, consumed power and sound pressure levels emitted by \\ centrifugal fans with the original model of 16 blades and the optimized \\ models of 16 and 14 blades are compared. Numerical calculations are \\ performed by the continuity equation, the Reynolds Averaged Navier- \\ Stokes (RANS) equations and the k- $\omega$ SST turbulence model. The quality of \\ the mesh is evaluated for three different mesh densities. Results \\ demonstrate that it was possible to obtain an increase of flow rate up to \\ $22.7 \%$, and reductions in the noise levels without increasing the \\ consumption of the electric motor. \\ Rua Sarnento Leite, 425, 90050 \\ Porto Alegre, Rio Grande do Sul, Brasi \\ leonardo.kothe@ufrgs.br \\ Received: October 31, 2016 \\ Revised: November 08, 2016 \\ Accepted: December 23, 2016 \\ Keywords: centrifugal fan, numerical simulation, experimental study
}

\section{NOMENCLATURE}

$\mathrm{b}_{1} \quad$ width at impeller inlet, $\mathrm{m}$

$\mathrm{b}_{2} \quad$ width at impeller outlet, $\mathrm{m}$

$\mathrm{C}_{2}$ impeller absolute velocity, $\mathrm{m} / \mathrm{s}$

$\mathrm{C}_{\mathrm{m} 1}$ absolute velocity at impeller inlet, $\mathrm{m} / \mathrm{s}$

$\mathrm{C}_{\mathrm{m} 2}$ absolute velocity at impeller outlet, $\mathrm{m} / \mathrm{s}$

$\mathrm{C}_{\mathrm{u} 2}$ circumferential component of the impeller mean absolute velocity, $\mathrm{m} / \mathrm{s}$

$\mathrm{D}_{1} \quad$ internal diameter, $\mathrm{m}$

$\mathrm{D}_{2} \quad$ external diameter, $\mathrm{m}$

$\mathrm{H}$ pressure head, mmca

$\mathrm{n}$ rotational speed, $\mathrm{rad} / \mathrm{s}$

$\Delta \mathrm{P} \quad$ pressure head, $\mathrm{Pa}$

$\mathrm{P}_{\mathrm{t}} \quad$ consumed power, $\mathrm{cV}$

$\mathrm{U}_{1}$; $\mathrm{U}_{2}$ peripheral velocities, $\mathrm{m} / \mathrm{s}$

$\mathrm{V}$ velocity, $\mathrm{m} / \mathrm{s}$

$\dot{V} \quad$ flow rate, $\mathrm{m}^{3} / \mathrm{s}$

$\mathrm{W}_{1} \quad$ impeller mean relative velocity, $\mathrm{m} / \mathrm{s}$

$\mathrm{W}_{2 \mathrm{u}}$ outlet impeller mean relative velocity, $\mathrm{m} / \mathrm{s}$

\section{Greek symbols}

$\beta_{1} \quad$ angle between the impeller peripheral and relative velocities at inlet, ${ }^{\circ}$

$\beta_{2} \quad$ angle between the impeller peripheral and relative velocities at outlet, ${ }^{\circ}$

$\eta \quad$ efficiency

\section{INTRODUCTION}

Centrifugal fans are extensively used in Industry and find applications such as dryers, heaters, climate control and agricultural applications. Experimental and, more recently, numerical studies are performed as attempts to improve the Energy efficiency of such equipment. Numerical analysis has been constantly employed to many types of research, thus requiring knowledge of the parameters to be used in order to create a model that adequately represents the real scenario. The Finite-Volume Method (FVM) allows for a real-like situation to be simulated, the results being cost reductions in $\mathrm{R} \& \mathrm{D}$, manufacturing and operation.

A number of studies are found in literature regarding centrifugal fans, covering radial-bladed devices as well as fans with bent blades, both forward and backward. Guo and Kim (2004) performed numerical simulations for forward-bladed fans, using an improvement to a slip factor model that takes into account the blade curvature. Reynolds-Averaged Navier-Stokes (RANS) Equations were used. Authors found that, by using the model and applying the adequate corrections, it is possible to obtain precise information about the mean absolute peripheral velocity downstream the impeller, this data being essential to the evaluation of a theoretical pressure raise. Bhope and Padole (2004) performed a theoretical and experimental analysis of the tensions involved in a rearward-bladed centrifugal fan. The study revealed a complex behavior of tensions in blades. Kim and Seo (2004) developed simplified models of impeller forces to determine an optimized shape to a forward-bladed fan. Parameters as cutoff 
location, cutoff ratio, expansion angle of scroll and width of impeller were changed and evaluated. Adachi, Sugita and Ohomori (2003) performed an experimental study focused on fan performance, in which the effects of changes in blade inlet and outlet angles were assessed using hot-wire anemometry for data collection. Twelve blade shapes with different angles were used for the experimental measurements.

The present work evaluates centrifugal fans of forward-bent blades, also known as Sirocco. This type of fan is extensively used in conditions that demand high flow rates, high efficiency and low noise (Guo and Kim, 2004). This fan finds applications in climate control of environments for Livestock, such as swine and poultry. This Paper brings both numerical and experimental analyses seeking to optimize the Sirocco by changing its shape and number of blades. The best results were selected using energy efficiency as the main criteria.

\section{DESIGN OF CENTRIFUGAL FANS}

The original centrifugal fan (described as the volute-impeller set) was modeled in 1:1 scale using appropriate 3D CAD software. Figure 1 shows the volute shapes. This part measures 0.837 meters of total height, having an outflow area measuring 0.078 $\mathrm{m}^{2}$. It is $0.36 \mathrm{~m}$ in internal diameter $\left(D_{1}\right), 0.52 \mathrm{~m}$ in external diameter $\left(D_{2}\right)$ and $0.15 \mathrm{~m}$ in impeller width $\left(b_{1}\right)$. Its outflow section is rectangular, having $0.26 \mathrm{~m}$ in width $\left(b_{2}\right)$ and $0.3 \mathrm{~m}$ in height. All metal sheets are $1.5 \mathrm{~mm}$ wide.

The 16-blade impeller has different blade inlet and outlet angles. In this case, a better aerodynamic shape was pursued by changing these angles only. The process for choosing the 14-blade impeller, in turn, involved an analytical estimate to improve the fan's flow rate and minimize the absorbed power.

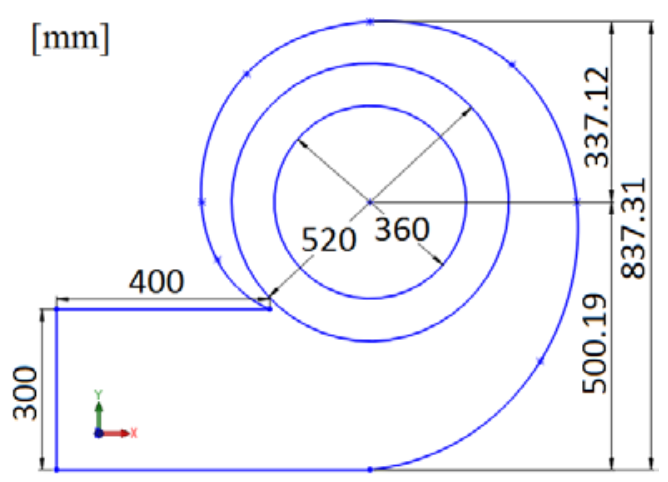

Figure 1. Geometry of the volute.

\section{ANALYTICAL ESTIMATE}

An analytical estimate was made using the velocity triangles equations described in the literature (White, 1998). These formulae allow for estimating pressure difference, flow rate and rated power of centrifugal fans for its respective dimensions. The aforementioned estimate is made by a set of equations obtained from White (1998), Fox, Pritchard and McDonald (2008) and Henn (2006). Figure 2 shows a scheme representing the main variables.

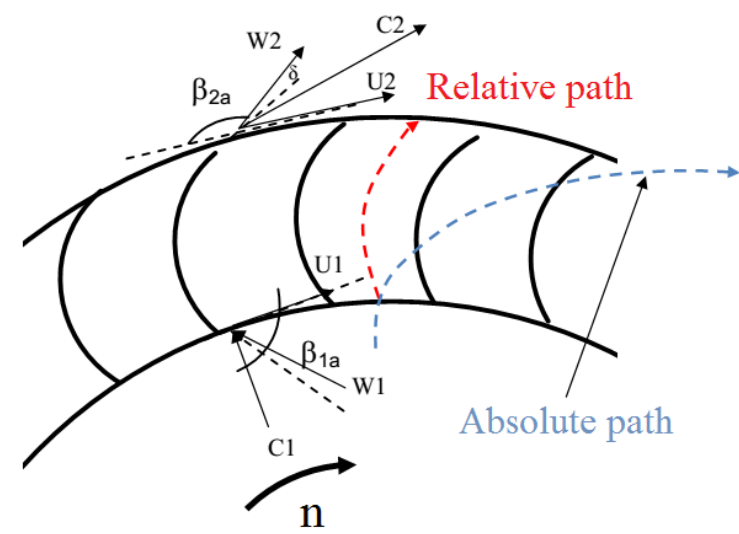

Figure 2. Schematic sketch of the variables.

The southerly component of the absolute velocity at the impeller inlet $\left(c_{m 1}\right)$ and at the outlet $\left(c_{m 2}\right)$ can be calculated using:

$$
\begin{gathered}
c_{m 1}=\frac{\dot{V}}{\pi D_{1} b_{1}} \\
c_{m 2}=\frac{\dot{V}}{\pi D_{2} b_{2}}
\end{gathered}
$$

in which $\dot{V}$ is the flow rate, $D_{1}$ is the internal diameter, $D_{2}$ is the external diameter, $b_{1}$ and $b_{2}$ the impeller widths. The peripheral velocities $U_{1}$ and $U_{2}$ can be calculated using:

$$
\begin{aligned}
& U_{1}=\frac{\pi n D_{1}}{2} \\
& U_{2}=\frac{\pi n D_{2}}{2}
\end{aligned}
$$

in which $n$ is the rotational speed of the blades.

The impeller mean relative velocity $W_{1}$ can be obtained by:

$$
W_{1}=\sqrt{c_{m 1}^{2}+U_{1}^{2}}
$$

The angle between the impeller peripheral and relative velocities $(\beta)$ can be calculated using:

$$
\beta_{1}=\tan ^{-1}\left(\frac{c_{m 1}}{U_{1}}\right)
$$



by:

The impeller absolute velocity $\left(C_{2}\right)$ is calculated

$$
C_{2}=\sqrt{c_{m 2}^{2}+c_{u 2}^{2}}
$$

where $c_{u 2}$ is the circumferential component of the impeller mean absolute velocity, being obtained by:

$$
c_{u 2}=U_{2}-W_{u 2}
$$

where $W_{u 2}$ is the impeller mean relative velocity. The angle $\beta_{2}$ is calculated by:

$$
\tan \beta_{2}=\frac{C_{m 2}}{W_{u 2}}
$$

The head $(H)$ and its conversion from mmca to Pa can be defined by:

$$
\begin{gathered}
H=\frac{U_{2} C_{2}-U_{1} c_{m 1}}{g} \\
\Delta P=H^{* 1.205}
\end{gathered}
$$

The consumed power $\left(P_{t}\right)$ by the system can be calculated by.

$$
P_{t}=\frac{1,205 \dot{V} H}{75 \eta}
$$

\section{NUMERICAL METHODOLOGY}

The ANSYS Fluent finite-volume commercial code is used to numerically solve the flow to which the centrifugal fans are subject. This uses the integral form of the conservation Equations as its starting point (Ferziger and Peric, 2002). Its working principle is to subdivide the solution domain into a finite number of adjacent control volumes, in which the conservation equations are applied. Then, an algebraic solution is obtained to each one of the control volumes, which in turn is solved iteratively, again for each control value (Patankar, 1980 and Maliska, 2004). The Continuity and Conservation of Linear Momentum Equations are solved by means of the RANS Equations, as explained by Wilcox (1998).

In order to solve the closing problem due to the use of RANS Equations, turbulence models have been created and studied. Models based on the Boussinesq Approach, that introduced the concept of Turbulent Viscosity $\left(\mu_{t}\right)$, are among the most used. Its purpose is to relate the turbulence with the mean flow to ultimately close the system of Equations (Wilcox, 1998). In the present work, the choice was to use the $k-\omega$ SST turbulence model. This model combines the original $k-\omega$ and the $k-\varepsilon$ models. According to Menter, Kuntz and Langtry (2003), its formulation is based on blending functions, which ensure an adequate selection of which model to use as a function of the zone in the domain without the need of interference from the user. The $k-\omega S S T$ model has been employed in a wide variety of studies, such as those by Jayapragasan, Suryawanshi and Reddy (2014), Jang, Lee and Yang (2013), Tsugita, Kowshik and Ohta (2012) and Kothe (2016).

\section{NUMERICAL DOMAIN}

The created mesh was divided into two domains, one for the volute and the other one to the impeller region. Both meshes were joined together using the Interface condition. Boundary conditions are atmospheric pressure at inlet, modeled by a semispherical geometry representing the exterior area, atmospheric pressure at outlet as well, and an imposed rotational speed of 1735 RPM at the region that comprises the impeller blades. All walls have the no-slip condition, so as to capture the viscous effects produced by the wall-fluid interaction. Turbulent intensity is $10 \%$ and the turbulent length scale is 0.01 $\mathrm{m}$. The simulations were performed in steady state. Mesh details are shown in Figure 3.

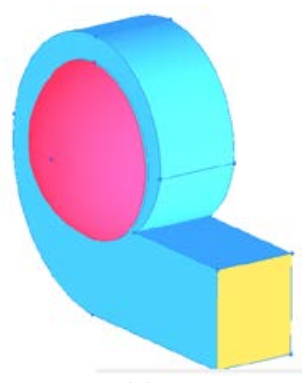

(a)

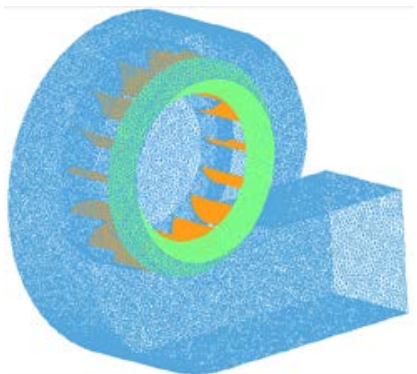

(b)
Figure 3. (a) geometry and (b) resulting grid.

\section{GRID QUALITY}

The grid quality is assessed by comparing three different mesh densities. The volume count at the region around the blades was kept constant in all cases, while the volume count in the domain comprising the volute was changed. Then, steadystate simulations were carried on, and results for parameters as mean velocity and flow rate at the outlet and pressure difference between inlet and outlet were compared. Grids and results for this process are shown in Table 1.

Table 1. Analysis for grid selection.

\begin{tabular}{|l|c|c|c|c|}
\hline Grid & Total & $\mathrm{V}[\mathrm{m} / \mathrm{s}]$ & $\dot{V}\left[\mathrm{~m}^{3} / \mathrm{s}\right]$ & $\Delta \mathrm{P}[\mathrm{Pa}]$ \\
\hline M1 & $4,668,245$ & 21.92 & 1.71 & 320.9 \\
\hline M2 & $3,830,742$ & 22.04 & 1.72 & 324.6 \\
\hline M3 & $2,906,629$ & 21.83 & 1.703 & 321.1 \\
\hline
\end{tabular}


Table 1 shows similar results for the three cases. The maximum difference in mean velocity is $0.4 \%$ between the finer and coarser meshes. Prism layers were created at the impeller region for better results around the blades, having been used 8 layers for each blade, for all the cases. These layers can be seen in detail in Figure 4.

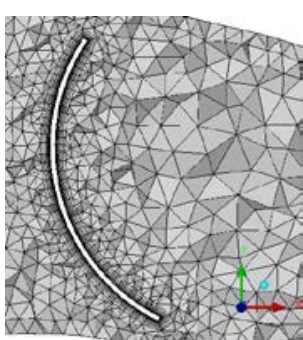

(a)

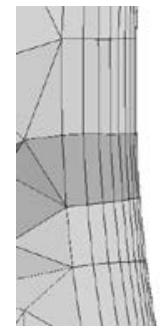

(b)
Figure 4. (a) blade detail and (b) prism layer.

\section{EXPERIMENTAL METHODOLOGY}

The experiments were performed with a fan that has been manufactured with the same dimensions of the numerical models. The fan is driven by a $5 \mathrm{CV}$ (4.93 HP) 4-poles electric motor built by Brazilian manufacturer WEG. Velocity was measured in 9 points at the outlet using a digital thermoanemometer model MDA-II. Current generated in each situation is also measured, what makes possible to measure their power consumption as well. This measurement is carried on using a digital clamp meter, model ET-3200. Blade rotational speed is measured with a photo-tachometer, model MDT2244B.

\section{NUMERICAL RESULTS}

Numerical simulations were carried on for the three types of fans: the original, 16 blade fan and the optimized 16 blade and 14 blade fans. Table 2 shows the results obtained at this stage, for a rotational speed of 1735 RPM.

Table 2. Numerical results.

\begin{tabular}{|l|c|c|}
\hline Geometry & $\mathrm{V}[\mathrm{m} / \mathrm{s}]$ & $\dot{V}\left[\mathrm{~m}^{3} / \mathrm{min}\right]$ \\
\hline 16 blades & 18.33 & 85.8 \\
\hline 16 blades, modified angle & 22.49 & 105.24 \\
\hline 14 blades & 23.34 & 109.26 \\
\hline
\end{tabular}

Figures 5, 6 and 7 show the velocity vectors at the volute core region for the 16-blade original design, 16-blade optimized and 14-blade optimized designs, respectively. In addition, figure 8 shows a detailed view of the flow that takes place between blades, again expressed as velocity vectors. These viewing aids can help visualizing the flow behavior during the design process. The aforementioned images show whether there is flow recirculation and volumetric internal losses, thus pointing where optimization procedures must be done.

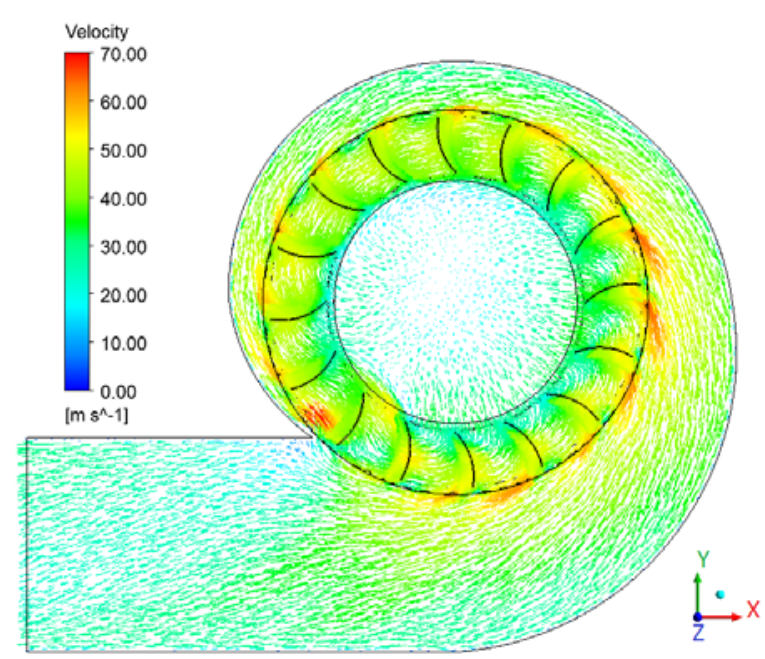

Figure 5. Vector field for the original 16-blade case.

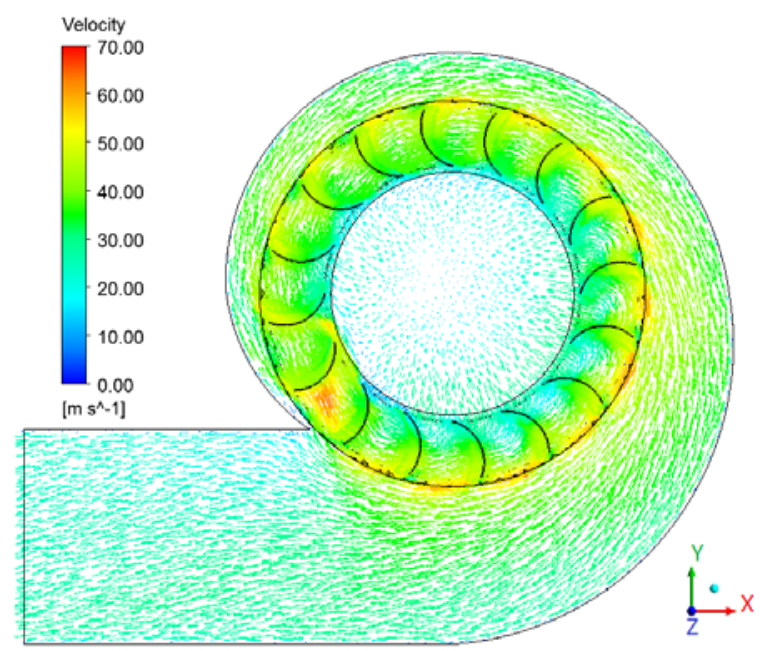

Figure 6. Vector field for the 16-blade optimized case.

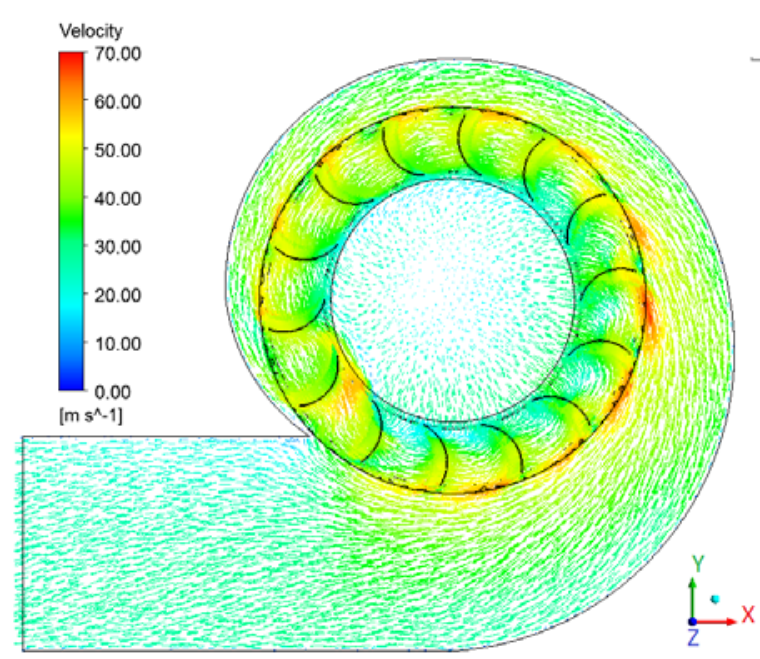

Figure 7. Vector field for the 14-blade optimized case. 
These vortices and recirculation zones that take place into the fan are the main responsible factors for poor performance, noise generation and head loss in the device.

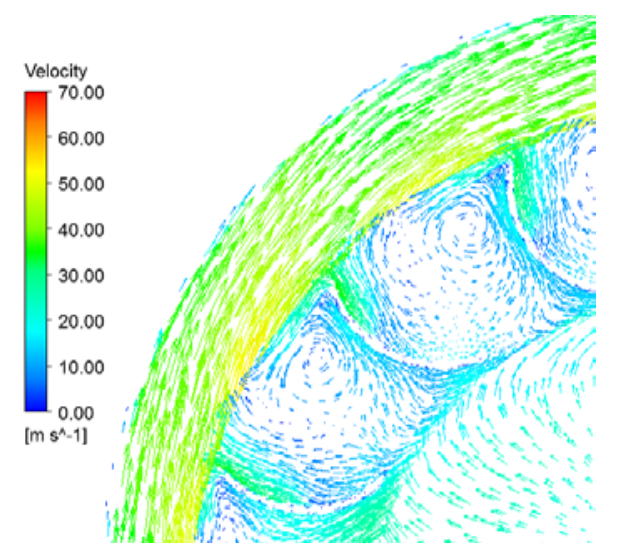

Figure 8. Vector field showing recirculation around blades.

\section{EXPERIMENTAL RESULTS}

This section presents the experimental results, which bring the values obtained by flow velocity measurements at different points, as well as electric current and noise data.

\section{Flow rate measurements}

Flow velocity measurements are performed at the outlet, which has an area equal to $0.078 \mathrm{~m}^{2}$. Figure 9 shows the 9 points where these measurements take place. Data collected allows the flow rate to be compared for each fan. Table 3 brings the measured data, in which it is possible to notice an increase in the flow rate equal to $22.7 \%$ and $20.4 \%$ when comparing the optimized 16-blade and 14 blade fans, respectively, to the original design.

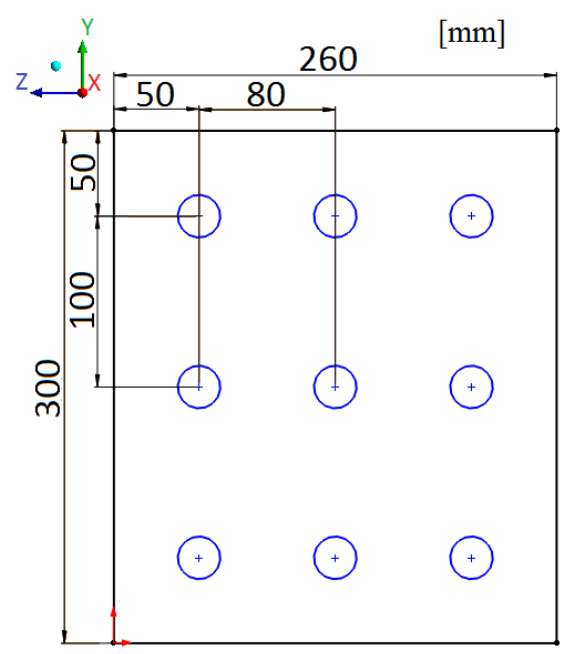

Figure 9. Location of measuring points.
Table 3. Measured data for flow rate and velocity.

\begin{tabular}{|c|c|c|c|c|}
\hline Meas. & $\begin{array}{c}16 \\
\text { blades }\end{array}$ & $\begin{array}{c}16 \text { blades, } \\
\text { modified angle }\end{array}$ & $\begin{array}{c}14 \\
\text { blades }\end{array}$ & Unit \\
\hline Average & 18.8 & 23.07 & 22.65 & $\mathrm{~m} / \mathrm{s}$ \\
\hline $\begin{array}{c}\text { Flow } \\
\text { rate }\end{array}$ & 88 & 108 & 106 & $\mathrm{~m}^{3} / \mathrm{min}$ \\
\hline
\end{tabular}

\section{Electric current measurements}

The electric current is measured using a DMM (Digital Multi Meter). Results collected at this stage allow comparing the power consumed by each device during operation. Table 4 shows electric current and power consumption for the fans under study. Measurements were performed three times for each fan, and the average values of each measuring run were calculated and used as representative value. Results show that power consumed didn't show any variation for any of the three cases, which demonstrates that a gain in flow rate was achieved without increasing power consumption.

Table 4. Measured data for electric current and consumed power.

\begin{tabular}{|c|c|c|c|c|}
\hline Meas. & $\begin{array}{c}16 \\
\text { blades }\end{array}$ & $\begin{array}{c}\text { 16 blades, } \\
\text { modified angle }\end{array}$ & $\begin{array}{c}14 \\
\text { blades }\end{array}$ & Unit \\
\hline $\begin{array}{c}\text { Electric } \\
\text { current }\end{array}$ & 16 & 16 & 16 & $\mathrm{~A}$ \\
\hline $\begin{array}{c}\text { Power } \\
\text { consumed }\end{array}$ & 3520 & 3520 & 3520 & $\mathrm{~W}$ \\
\hline
\end{tabular}

\section{Noise measurements}

Noise generated by each fan was also measured and compared. Once again, measurements were performed three times for each case, and its average values are shown in Table 5 . Collected data allow to analyze a reduction in the noise produced, for which a higher noise level was obtained for the original design, whereas the optimized designs produced lower levels. Reduction was $7.16 \%$ for the 16-blade optimized design and $9.52 \%$ for the 14-blade design, respectively compared to the data collected for the original design.

Table 5. Measured data for noise.

\begin{tabular}{|c|c|c|c|c|}
\hline Meas. & $\begin{array}{c}16 \\
\text { blades }\end{array}$ & $\begin{array}{c}16 \text { blades, } \\
\text { modified angle }\end{array}$ & $\begin{array}{c}14 \\
\text { blades }\end{array}$ & Unit \\
\hline Average & 84 & 78 & 76 & $\mathrm{~dB}$ \\
\hline
\end{tabular}

\section{CONCLUDING REMARKS}

This study presented both numerical and experimental analyses on the performance of industrial centrifugal fans, commonly used for ventilation and climate control for livestock sheds. Results obtained were deemed as satisfactory, for which it was possible to obtain considerable improvements in power consumption by only making 
changes in the shape and number of blades of a standard centrifugal fan. Numerical modelling and simulations allowed for visualizing flow patterns and locating possible spots in the device geometry to be improved, such as recirculation and stagnation points. Numerical and experimental results differ in about $2 \%$ but, since measurement uncertainties are about $5 \%$, that difference is inside the margin of error. Regarding to the noise issue, a reduction of $6 \mathrm{~dB}$ and $8 \mathrm{~dB}$ was detected for the 16-blade and 14-blade optimized designs, respectively, when compared to the 16-blade original design.

The experimental measurements revealed interesting results regarding to power consumption, since it didn't show any variation at the same time that increases in flow rate were detected for both the optimized designs. Both optimized designs also shown a reduction in generated noise, although only the blades were redesigned. For future studies, new blade and even volute shapes can be evaluated in pursuit of improvements in flow rate, pressure, noise, power consumption, among others.

\section{ACKNOWLEDGEMENTS}

The authors would like to acknowledge CAPES for the financial support of this research.

\section{REFERENCES}

Adachi, T., Sugita, N., and Ohomori, S., 2003, Study on the Effects of Flow in the Volute Casing on the Performance of a Sirocco Fan, Journal of Thermal Science, Vol. 13, No. 3, pp. 199-206.

Bhope D. V., and Padole, P. M., 2004, Experimental and Theoretical Analysis of Stresses, Noise and Flow in Centrifugal Fan Impeller, Mechanism and Machine Theory, Vol. 39, No. 12, pp. 1257-1271.

Ferziger, J. H., and Peric, M., 2002, Computational Methods for Fluid Dynamics, 3rd edition, Springer.

Fox, R. W., Pritchard, P. J., and McDonald, A. T., 2010, Introdução à Mecânica dos Fluidos, $7^{\text {a }}$ Edição, LTC. (in Portuguese)

Guo, E. M., and Kim, K. Y., 2004, ThreeDimensional Flow Analysis and Improvement of Slip Factor Model for Forward-Curved Blades Centrifugal Fan, KSME International Journal, Vol. 18, No. 2, pp. 302-312.

Henn, E. A. L., 2006, Máquinas de Fluido, $2^{\mathrm{a}}$ Edição, Editora UFSM. (in Portuguese)

Jang, C. M., Lee, J. S., and Yang, S. H., 2013, Performance Evaluation of a Centrifugal Blower Using Optimal Design Method, Fluids Engineering Division Summer Meeting.

Jayapragasan, C. N., Suryawanshi, S. J., and Reddy, K. J., 2014, Design Optimization of Centrifugal Fan of Travelling Cleaner, ARPN Journal of Engineering and Applied Sciences, Vol. 9, No. 9, pp. 1637-1644.

Kim, K. Y., and Seo, S. J., 2004, Shape Optimization of Forward-Curved-Blade Centrifugal Fan with Navier-Stokes Analysis, Journal of Fluids Engineering, Vol. 126, No. 5, pp. 735-742.

Kothe, L. B., 2016, Estudo Comparativo Experimental e Numérico Sobre o Desempenho de Turbinas Savonius Helicoidal e de Duplo-Estágio, Master Thesis, PROMEC-UFRGS, Porto Alegre, RS. (in Portuguese)

Maliska, C. R., 2004, Transferência de Calor e Mecânica dos Fluidos Computacional, 2a Edição, LTC. (in Portuguese)

Menter, F. R., Kuntz, M., and Langtry, R., 2003, Ten Years of Industrial Experience with the SST Turbulence Model, Turbulence Heat and Mass Transfer, Vol. 4, pp. 625-362.

Patankar, S. V., 1980, Numerical Heat Transfer and Fluid Flow, McGraw-Hill.

Tsugita, D., Kowshik, C. K. P., and Ohta, Y., 2012, Visualization of Rotating Vortex in a Centrifugal Blower Impeller, Journal of Visualization, Vol. 15, pp. 207-214.

White, F. M., 1998, Fluid Mechanics, 4th Edition, McGraw-Hill.

Wilcox, D. C., 1998, Turbulence Modeling for CFD, DCW Industries. 